\title{
Modelos implementados en el análisis de series de tiempo de temperatura superficial e índices de vegetación: una propuesta taxonómica en el contexto de cambio climático global
}

\section{Models implemented in the land surface temperature and vegetation indexes time series analysis: a taxonomic proposal in the context of the global climate change}

\author{
Oscar Arley Zuluaga Gómez (D), Jorge Eduardo Patiño Quinchía² (D) \\ y German Mauricio Valencia Hernández ${ }^{3}$ (10
}

\begin{abstract}
RESUMEN
El cambio climático y el calentamiento global son provocados principalmente por las actividades antrópicas. Por esta razón, conocer las líneas de investigación que relacionen Series de Tiempo de Temperatura Superficial e Índices de Vegetación es de suma importancia, dada la amplitud de las diferentes áreas científicas abiertas sobre el calentamiento global. Se presenta a la comunidad académica, por tanto, el resultado de la presente clasificación, la cual divide los estudios en dos áreas principales representativas en el estudio del cambio climático: (1) Modelado y Análisis de Geodatos y (2) Teledetección. De este último se derivan dos tipos, unos construidos con Análisis de Regresión Lineal (RL) y otros con Análisis de Regresión No Lineal (RNL). En el Modelado y Análisis de Geodatos, los Modelos Climáticos Globales (GCM) no son la herramienta adecuada para estos análisis debido a su gruesa resolución espacial. Esto implica el desarrollo de modelos híbridos con teledetección, que están también limitados por las diferencias de resolución. Por el contrario, la teledetección es la herramienta de mayor difusión para este tipo de estudios. Finalmente, se abre una prometedora ventana para el desarrollo en las series de tiempo con análisis de Regresión No Lineal.
\end{abstract}

Palabras Clave: Series de Tiempo, Índices de Vegetación, Calentamiento Global, GCM, Análisis de Regresión Lineal, Análisis de Regresión No Lineal.

\section{ABSTRACT}

Climate change and global warming are caused principally by anthropogenic activities. For this reason, understanding the research lines that relate Land Surface Temperature and Vegetation Index time series is of great importance, given the amplitude of different open scientific areas on global warming. The result of this classification is presented to the academic community, which divides the studies into two main representative areas

Especialista en Sistemas de Información Geográfica, Candidato MSc Geoinformática Universidad de San Buenaventura Sede Medellín E-mail: oazuluag@unal.edu.co

Investigador Senior, Grupo de Investigación Research In Spatial Economics (RiSE) Universidad EAFIT. Departamento de Economía. E-mail: jpatinoq@eafit.edu.co

MSc en Geoinformática Profesor de Planta Facultad de Ingeniería Universidad de San Buenaventura Sede Medellín

E-mail: german.valencia@usbmed.edu.co 


\begin{abstract}
in the study of climate change: (1) Geodata Modeling and Analysis and (2) Remote Sensing. From the last one, two types are derived, some constructed with Linnear Regression Analysis (RL) and others with Nonlinear Regression Analysis (RNL). On the Geodata Modeling and Analysis, the Global Climate Models (GCM) are not the right tool for these analyzes due to their coarse spatial resolution. This implies the development of hybrid models with remote sensing, which are also limited by differences in resolution. On the other hand, remote sensing is the most widely disseminated tool for this type of studies. Finally, a promising window for development in the time series opens with non-linear regression analysis.
\end{abstract}

Keywords: Time Series, Vegetation Index, Global Warming, GCM, Linear Regression Analysis, Nonlinear Regression Analysis.

\title{
Introducción
}

El calentamiento global, el cambio climático y el efecto invernadero son términos ya conocidos en la sociedad y son de uso común en el lenguaje cotidiano. Dicha condición se evidencia a diario con fenómenos como la fusión de los glaciares, el derretimiento del hielo en zonas polares y el incremento de los eventos climáticos extremos (Ramachandran, Justice y Abrams 2011). Los valores de temperatura media, a nivel mundial, presentaron sus máximos históricos en el primer semestre del año 2016 (CINU 2016) y los años 2015, 2016 y 2017 podrían ser los más calurosos desde que existen registros (WMO 2017; ECMWF 2017). Se destacan las fuertes sequías asociadas al fenómeno del niño (Saatchi et al. 2013), siendo el periodo 2015-2016 el segundo más fuerte de la historia (IDEAM 2016). La actividad humana ha impactado sustancialmente el equilibrio ambiental en la Tierra debido al uso excesivo de hidrocarburos, que han liberado millones de toneladas de monóxido de carbono y otros elementos que son dañinos para la atmósfera y han afectado el comportamiento del clima a nivel global y el ciclo de carbono (IPCC 2014; Barker 2007; Wofsy et al. 2007). Esto ha alterado el equilibrio ambiental en el planeta debido al aumento de gases de efecto invernadero. Las actividades antrópicas han provocado el cambio en los usos del suelo, que generan erosión y provocan modificaciones en el clima, que a su vez tienen como consecuencia el aumento en la intensidad y frecuencia de eventos climáticos extremos y de incendios forestales (García-Mora y Mas 2011; Rodríguez Eraso, Armenteras-Pascual y Alumbreros 2013; Turner y Gardner 2015), además de la disminución en la provisión de servicios ecosistémicos (Vilardy et al. 2011; Zedler y Kercher 2005; Zurqani et al. 2018).

Rodriguez Erazo et al. (2010) estimó que los ecosistemas de páramo en Colombia podrían reducirse hasta en un $97 \%$ por el aumento en la altura del piso térmico a partir del cual se encuentran. Igualmente, los bosques de niebla se verán afectados debido al aumento de la temperatura, lo que evitará la formación de nubes a baja altura, que son las encargadas de llevar la humedad hasta ellos. Según las estimaciones más recientes, a finales del siglo XXI habrá aumentado la temperatura $4^{\circ} \mathrm{C}$ y se reducirán las precipitaciones en un $50 \%$ en la región del altiplano andino colombiano, mientras que aumentará en un $30 \%$ en la vertiente del pacífico del país; esto sin mencionar el retroceso en los glaciares, donde Colombia ha perdido el $84 \%$ de su área en poco más de 100 años (IDEAM 2012).

Una importante evidencia del cambio climático y el calentamiento global en las coberturas vegetales es el cambio en las características estacionales y de desarrollo de la vegetación (fe- 
nología) (Bonan 2008; Zhao y Running 2010; Anaya Acevedo y Valencia Hernandez 2013; Anaya, Colditz y Valencia 2015). En este marco, puede decirse que las sequías asociadas al fenómeno del niño afectan visiblemente la cobertura vegetal: aumentan la susceptibilidad a incendios forestales, la mortandad de árboles, y disminuye la salud y turgencia de los mismos (Saatchi et al. 2013). Es en este punto en que la información derivada de los sensores remotos se convierte en una importante herramienta para detectar estas variaciones (Li, Qu y Hao 2010; Colditz y Dech 2007; Hermosilla et al. 2015; Vogelmann et al. 2012). Lo anterior es posible debido a que existe una gran relación entre los índices de vegetación (IV) y la biomasa aérea, el verdor de la vegetación y en general el estado de salud de la cobertura vegetal (Anaya, Chuvieco y Palacios 2008). La región espectral del infrarrojo cercano (NIR) es especialmente sensible para hacer seguimiento al área foliar y a la actividad fotosintética de la vegetación (Huete et al. 1997).

Las actuales tendencias climáticas, así como su afectación sobre la cobertura vegetal, han motivado en todo el mundo una variedad de investigaciones al respecto. Sin embargo, aún existe incertidumbre en las tendencias y resultados en los modelos climáticos y su afectación en la biomasa, debido a que no existen datos suficientes para establecer tendencias precisas (Bravo Peña et al. 2013), sus efectos a largo plazo en la selva amazónica son desconocidos y los conocimientos de las coberturas tropicales son limitados (Setiawan, Yoshino y Prasetyo 2014; Saatchi et al. 2013). Lo anterior evidencia que aún falta desarrollo en esta área para la región del trópico.

Los sensores remotos satelitales cuentan con una alta resolución espacial, temporal y espectral lo que les da la capacidad de monitorear los cambios y el desarrollo de la vegetación a través de grandes áreas con una alta precisión (Hansen y Loveland 2012; Chen et al. 2014; Ottinger et al. 2013; Mishra, Ghosh y Ghosh 2012; Song y Bo 2011). Esto permite la construcción de series de tiempo para evaluar los cambios de la cobertura terrestre e identificar cambios abruptos (Colditz y Dech 2007). Desde los años 60 se inició el reconocimiento de los fenómenos terrestres a través de la teledetección (Rincón Romero, Jarvis y Mulligan 2012). La misión EOS (Earth Observation System) es una de las más reconocidas. El sensor MODIS se destaca dentro de la EOS, ya que sus instrumentos fueron diseñados para obtener información diaria, continua, global y multitemporal para la observación terrestre (García-Mora y Mas 2011). Dichos instrumentos permiten obtener registros integrales de los océanos, la tierra y la atmósfera con diferentes productos, entre ellos varios Índices de Vegetación (IV), como el Índice de Vegetación de Diferencia Normalizada (NDVI), el Índice de Vegetación Mejorado (EVI), el Índice de Área Foliar (LAI), entre otros además del registro de Temperatura Superficial Terrestre (LST) (Ramachandran, Justice y Abrams 2011). Aprovechando esta versatilidad, se han utilizado estos IV para detectar los cambios en las coberturas debido al cambio climático (Son et al. 2012). Por otro lado, los sensores térmicos infrarrojos han sido aplicados con éxito en estudios ambientales y climáticos, principalmente para analizar los patrones de temperatura superficial y relacionarlos con las características del paisaje (Weng, Lu y Schubring 2004; Weng 2009; Rajasekar y Weng 2009).

En este trabajo se realiza una revisión de la literatura científica sobre esta materia y una comparación entre los métodos de análisis utilizados para el estudio del comportamiento de la temperatura superficial y su relación con los índices de vegetación, con el fin de conocer el nivel en el que se encuentra el campo de investigación. Además, se presenta una propuesta para la clasificación de las tendencias en investigación para dicha área, y así identificar los diferentes métodos utilizados para el análisis de los datos y los modelos estadísticos más apropiados. 


\section{Propuesta metodológica}

Para el presente artículo de revisión se acudió, como fuente principal de consulta, a la Base de Datos Científica Scopus, la cual contiene el más grande archivo de artículos científicos aprobados por pares académicos (Elsevier 2018). Adicionalmente, se utilizaron técnicas bibliométricas para el análisis de las tendencias en investigación, las cuales consisten en el análisis de la producción y el consumo de bibliografía científica (Ardanuy y Rey 2012).

Dentro del campo de la geoinformática existen diversas áreas de investigación que pueden variar en su organización, dependiendo de los intereses o condiciones particulares del programa curricular que las adelante. Una de estas formas establece cuatro fases para la solución de problemas geoinformáticos, en la que cada fase comprende un área de desarrollo como línea de investigación. Las fases son: (1) Adquisición y Edición de Geodatos, (2) Estructuración y Almacenamiento de Geodatos, (3) Modelado y Análisis de Geodatos, y por último, (4) Despliegue de Geodatos (Valencia et al. 2017), como se observa en la Figura $N^{\circ} 1$.

Figura $\mathrm{N}^{\circ} 1$

Fases para solucionar un problema con componente geo informático

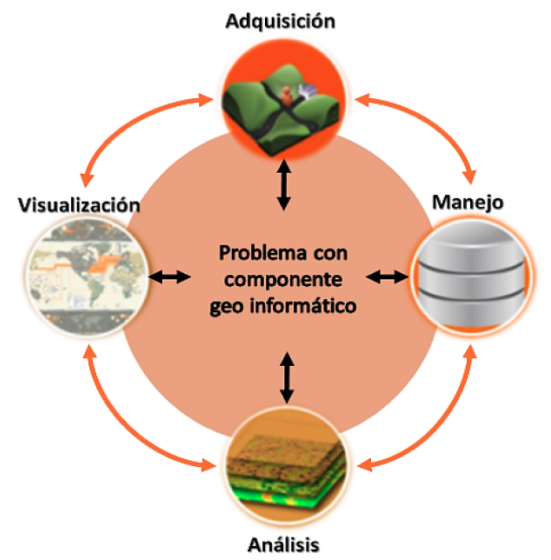

Fuente:(Valencia et al. 2017)

A la luz de este discernimiento, los cambios de temperatura producidos por acción del cambio climático se pueden analizar a partir de la geoinformática desde dos de sus procesos o ramas de estudio. La primera comprende la Adquisición y Edición de Geodatos, la cual es conformada en parte por el levantamiento de la información mediante el uso de sensores remotos (Valencia et al. 2017). La segunda corresponde al Modelado y Análisis de Geodatos, grupo de competencias encargadas del análisis de datos mediante técnicas, que pueden ser geoestadísticas o análisis de variables espaciales (Valencia et al. 2017). Se debe tener en cuenta que, aunque son las herramientas principales en el presente análisis, no se excluyen de ninguna manera los otros dos componentes, los cuales son parte integral de la solución de cualquier problema en geoinformática (Valencia et al. 2017). En cuanto a la modelación, debe mencionarse que esta se define como la representación matemática de los procesos físicos que abarcan el comportamiento de la hidrósfera, la atmósfera, la criósfera, y que pueden simular su comportamiento y su tendencia en el futuro (Barros 2005). 
Tanto en la Adquisición como en el Modelado es posible obtener tendencias desde el punto de vista del comportamiento de la información en una línea de tiempo (Series de Tiempo). Sin embargo, los métodos más eficaces para el estudio de cambios en las coberturas vegetales se basan en el uso de sensores remotos (Chan y Xu 2013; Parihar et al. 2013; Klemas 2013; Gibbes, Southworth y Keys 2009; Ottinger et al. 2013). Esto es así, dado que son una alternativa de bajo costo para estudios de áreas muy grandes, siendo el caso del uso de imágenes satelitales de resolución espacial alta y media, tales como las plataformas Landsat, CBERS-02, y MODIS (Chan y Xu 2013). Por lo tanto, la utilización del modelado y la simulación espacial tendrían que desarrollarse de manera combinada. Estos análisis pueden ser simples, representados mediante líneas de tendencia o regresiones lineales, las cuales solo presentan una aproximación a su comportamiento en el lapso temporal bajo evaluación (Mudelsee 2018; Eckert et al. 2015; Livada et al. 2019). Igualmente, se presentan estudios con obtención de resultados con una estadística sólida, bajo el análisis de series de tiempo sujetas a una mayor rigurosidad en las que se implementan modelos estadísticos y econométricos (Gujarati y Porter 2010; Salles et al. 2018; Saatchi et al. 2013; Bravo Peña et al. 2013).

Mediante el presente estudio se pretende elaborar una revisión bibliográfica de los diferentes modelos implementados en el análisis de series de tiempo que comparan Índices de Vegetación (IV) y Temperatura Superficial (LST). Esto con el fin de establecer una clasificación que pueda identificar vacíos en el conocimiento, siguiendo el diagrama presentado en la Figura $N^{\circ} 2$.

Figura $\mathrm{N}^{\circ} 2$

Diagrama de flujo propuesta para clasificación de investigaciones

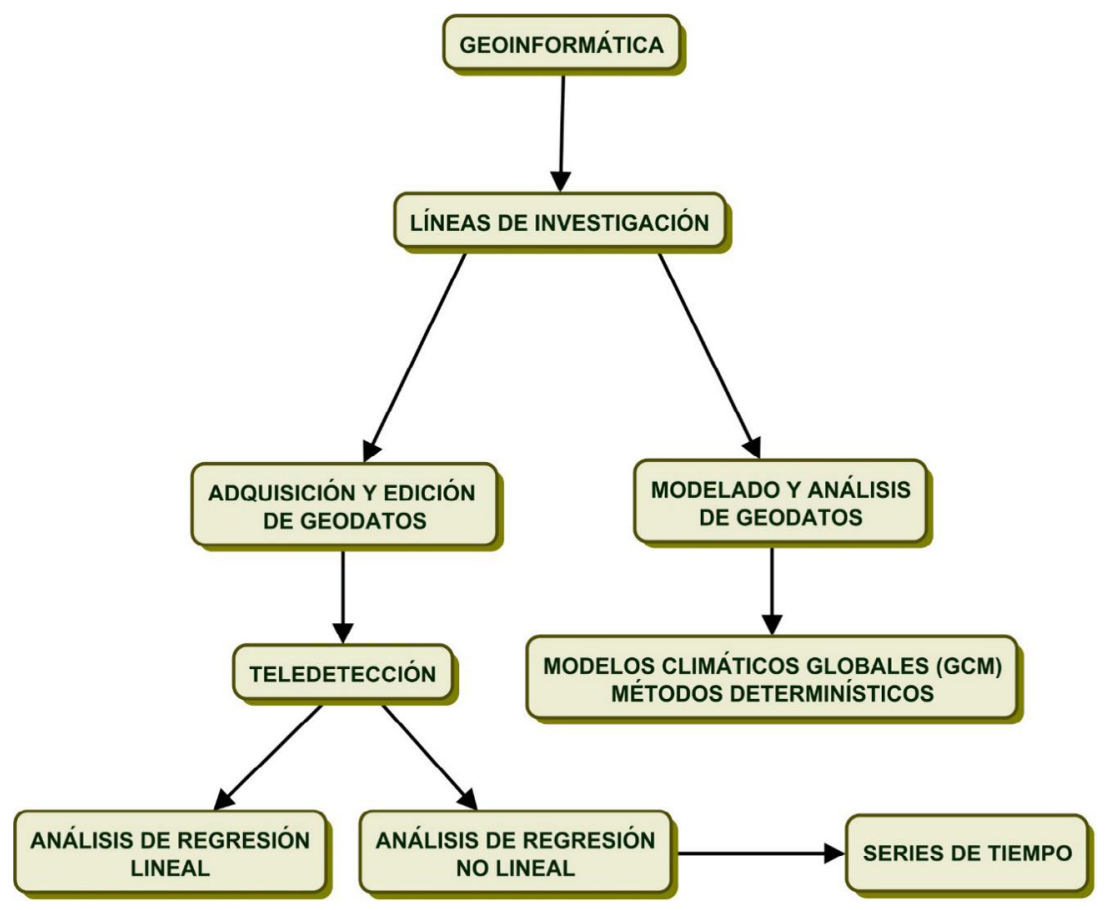

Fuente: Elaboración propia. 


\section{Propuesta de clasificación}

Dentro del amplio espectro de la investigación del cambio climático y el calentamiento global se encuentra la temática correspondiente a su efecto sobre las coberturas vegetales, dado que esta tiene una gran sensibilidad al clima (Anaya Acevedo y Valencia Hernandez 2013). Entre los métodos más usados actualmente está el análisis de series de tiempo a partir de los sensores remotos, aunque desde el ámbito científico o académico el tema se ha abordado desde diversas metodologías. Uno de los parámetros bajo estudio es la temperatura, para lo cual el análisis de sus cambios se ha abordado de dos maneras. La primera corresponde al análisis de tendencias a partir de series de tiempo y la segunda corresponde a la simulación de escenarios de emisión utilizando Modelos Climáticos Globales (GCM), con los que se obtienen predicciones del comportamiento del clima a futuro (Ma et al. 2016).

\section{Modelado y análisis de geodatos}

En la literatura es posible encontrar estudios que no incluyen sensoramiento remoto (imágenes satelitales) o que no utilizan herramientas que se basan principalmente en teledetección. Dichos estudios utilizan índices ambientales, medición directa en campo o modelos matemáticos, además de métodos determinísticos para la interpolación espacial de los datos. Un ejemplo de ellos es el estudio de Vargas Cuervo y Gómez (2003), el cual utiliza indicadores climáticos, bióticos, edafológicos y de intensidad de degradación para construir un modelo del avance de la desertificación en Colombia. Los autores usaron un sistema de información geográfica, basado en superposición de capas, para construir un modelo sencillo de análisis estadístico univariado. El estudio tomó como referencia mapas de degradación de suelos y tierras del país, y encontraron que los desiertos del país podrían tener en 100 años un crecimiento del 3,1\%, para un total de más de 8 millones de hectáreas, que equivalen al 7,2\% del territorio nacional. De otro lado, también se presentan estudios como el de Viola, Paiva y Savi (2010) quienes presentan análisis de series de tiempo de temperatura tomado de datos meteorológicos de estaciones puntuales, ubicadas en 8 ciudades representativas del mundo: Montreal, Los Angeles, Río de Janeiro, Johannesburgo, Albany, Londres, Beijing y Tokio. Además, estimaron el aumento de la temperatura en promedio de $0.29^{\circ} \mathrm{C}$ para el año 2028 , utilizando Técnicas de Predicción No-Lineal Simple.

Igualmente, dentro de la temática del cambio climático se encuentran los Modelos de Circulación General, también llamados Modelos Climáticos Globales (GCM). Estos modelos son hasta ahora los más avanzados para el estudio del clima, e integran en estos diversas variables reportadas por el Panel Internacional de Cambio Climático (IPCC) (Conde y Gay García 2008). Sin embargo, los GCM son de acceso limitado, dado que solo son desarrollados por grandes instituciones como universidades y centros de investigaciones climáticas, sujetas a sus necesidades particulares (Armenta et al. 2014; Conde y Gay García 2008). Dentro de los estudios que utilizan esta metodología se destaca el de Villers Ruiz y Trejo Vazquez (1998), quienes utilizaron Modelos GCM para México y específicamente varios de sus parques naturales, para simular condiciones del clima actual. Utilizan el modelo Canadian Climate Centre Model (CCCM) y el modelo Geophysical Fluid Dynamics Laboratory (GFDL-R30). Encontraron que el 13\% de los bosques templados-fríos y templados-cálidos de México tienden a desaparecer, mientras que los bosques tropicales espinosos, 
asociados a climas cálidos y secos con temperaturas superiores a los $24^{\circ} \mathrm{C}$, tienden a aumentar. Sun et al. (2018) utilizan un modelo COSMO-CLM (CCLM) para estimar los cambios futuros en la precipitación bajo un escenario de incremento de $1.5^{\circ} \mathrm{C}$ a $2.0^{\circ} \mathrm{C}$ en la temperatura media global. Los autores encontraron que bajo estas condiciones de aumento de la temperatura, el sudeste de China sufrirá mayores precipitaciones, aumentando el riesgo de inundaciones, mientras que en el centro y el norte del país disminuirán y aumentarán los riesgos de sequía. Otros autores como Xu et al. (2017) basan sus trabajos en modelos como el CMIP Fase 5 (CMIP5), encontrando que respecto a la era preindustrial, las temperaturas y las precipitaciones medias sobre Asia han tenido un incremento hasta de $6.0^{\circ} \mathrm{C}$ en la temperatura y hasta de un $13 \%$ en la precipitación; adicionalmente, se proyecta una mayor amplitud en sus valores extremos, superiores a los valores de cambio promedio global bajo varios escenarios de calentamiento. Igualmente, Shi et al. (2018) utiliza entre 20 y 27 Modelos Climáticos Globales (GCM), que conforman el CMIP5 para identificar los cambios en las temperaturas extremas sobre China bajo los escenarios de calentamiento de $1.5^{\circ} \mathrm{C}$ y $2.0^{\circ} \mathrm{C}$ con simulaciones de las Vías de Concentración Representativa (RCP) de RCP2.6, RCP4.5 y RCP8.5; en ella encontraron que los aumentos en la temperatura media y extremas son mayores a la media global hasta en $1.8^{\circ} \mathrm{C}$. Li, Tao et al (2019) utilizan los GCM del Proyecto Intersectorial de Modelos de Intercomparación de Impactos (ISI-MIP), encontrando que Asia Central experimentará inviernos más cálidos y húmedos en los niveles de calentamiento global de $1.5^{\circ} \mathrm{C}$ y $2.0^{\circ} \mathrm{C}$, cuestión asociada al aumento de las precipitaciones de nieve en las regiones del noroeste de dicha región de Asia.

En general, los Modelos Climáticos Globales (GCM) y sus variantes, Modelos de Sistemas Terrestre (ESM) u otros, son modelos matemáticos complejos que simulan el comportamiento de la atmósfera, océanos y superficie terrestre en 3 dimensiones (Anderson, Hawkins y Jones 2016; Reshmidevi et al. 2018). Estos modelos manejan una resolución relativamente gruesa a escalas globales que, además, introducen grandes valores de incertidumbre a escalas más detalladas (Anderson, Hawkins y Jones 2016; Reshmidevi et al. 2018). De esta forma se realizan contrastaciones sistematizadas de dichos modelos, con miras a darle confiabilidad mediante la comparación entre modelos, como el proyecto CMIP5 con modelaciones para todo el Siglo XXI (Armenta et al. 2014). Autores como Zhou et al. (2017) indican que en la progresión desde el CMIP3 se han mejorado algunos aspectos, aunque aún se mantienen sesgos e incertidumbres asociados a la predicción de lluvias y que son evidentes en los modelos CMIP5.

Al ingresar las palabras claves "Temperature Time Series" y "GCM" en el portal Scopus (Base de datos) para artículos científicos presentados desde el año 1997, se observa que no abundan las investigaciones que relacionen ambos aspectos de la búsqueda, menos de un artículo por año. Esto puede interpretarse como la poca utilización de estas herramientas matemáticas debido a su baja resolución y su propia complejidad en el cálculo, sumado a la abundancia temática que ofrecen las imágenes de los sensores remotos que son de fácil consulta y adquisición (Figura $\left.N^{\circ} 3\right)$.

Igualmente, si se agrega al criterio de búsqueda la palabra clave "Vegetation Index" se obtienen resultados aún menos numerosos en investigaciones que relacionen el calentamiento global con el cambio en las coberturas vegetales y los modelos GCM (Figura $N^{\circ} 4$ ). 
Figura $\mathrm{N}^{\circ} 3$

Artículos presentados por año con criterios de búsqueda Temperature Time Series AND GCM

Documents by year

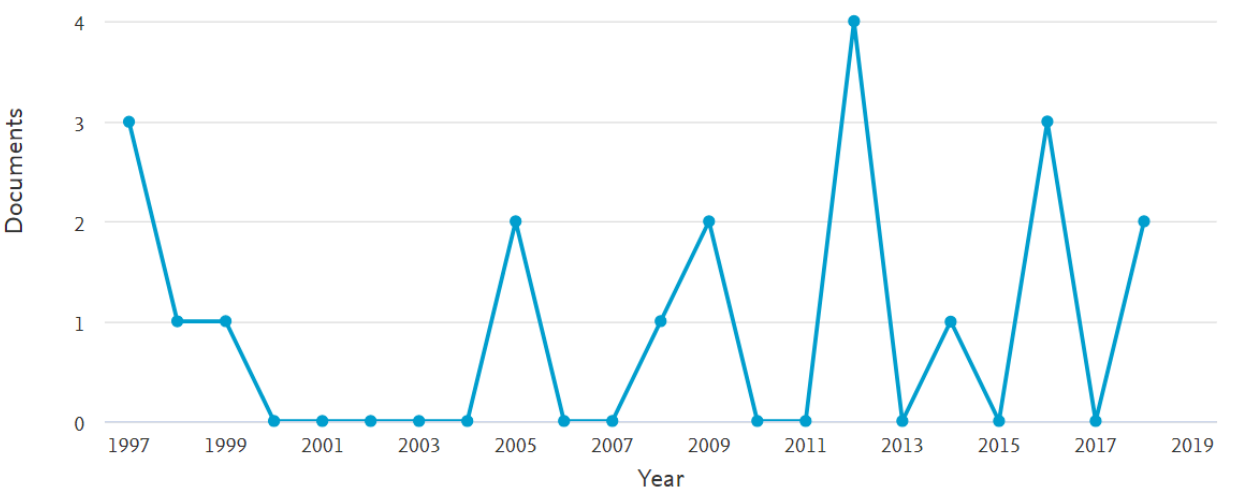

Fuente: (Elsevier 2018)

Figura $\mathrm{N}^{\circ} 4$

Artículos presentados por año con criterios de búsqueda Temperature Time Series AND GCM AND Vegetation Index

Documents by year

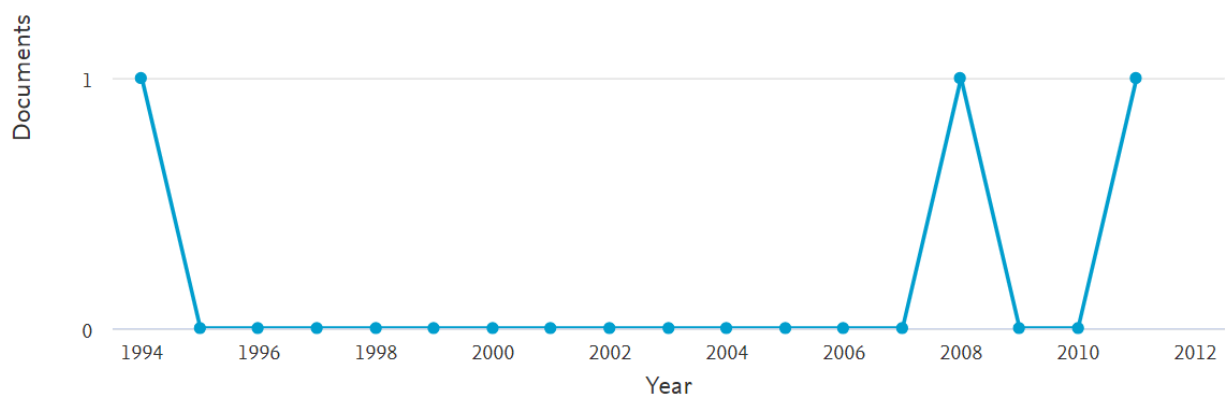

Fuente: (Elsevier 2018)

Al observar el Cuadro $N^{\circ} 1$ se aprecian con mayor claridad las limitaciones de este grupo de investigaciones, debido a que no son utilizadas ampliamente para relacionar el comportamiento climático con sus efectos sobre la vegetación. Igualmente puede apreciarse su limitación espacial, ya que no son muy extendidas en la región tropical de Suramérica. 
Debe tenerse en cuenta que estas metodologías, aunque cuentan con amplio sustento científico, han sido opacadas en su desarrollo debido al auge de los sensores remotos, los cuales ofrecen información más amplia, precisa y de mayor resolución espacial. Adicionalmente, no permiten realizar una relación directa pixel a pixel entre la temperatura obtenida de los modelos y los índices de vegetación, los cuales son extraídos por medio de satélites desde el espacio; esta comparación de datos de temperatura se puede realizar directamente con sensores como MODIS, Landsat y Sentinel, entre otros.

Cuadro $\mathrm{N}^{\circ} 1$

Criterios para la búsqueda de información de Series de Tiempo, Modelos GCM e Índices de Vegetación.

\begin{tabular}{|l|c|c|c|c|}
\hline & $\begin{array}{c}\text { "Temperature } \\
\text { Time Series" }\end{array}$ & "GCM" & $\begin{array}{c}\text { "Temperature } \\
\text { Time Series" } \\
\text { AND GCM }\end{array}$ & $\begin{array}{c}\text { "Temperature Time } \\
\text { Series" AND GCM AND } \\
\text { "Vegetation Index" }\end{array}$ \\
\hline Todos los documentos & 993 & 14695 & 20 & 3 \\
\hline Solo revistas académicas & 876 & 13095 & 17 & 2 \\
\hline $\begin{array}{l}\text { Solo textos de Ciencias de la } \\
\text { tierra, relacionadas con clima } \\
\text { y calentamiento global }\end{array}$ & 784 & 10151 & 16 & 2 \\
\hline $\begin{array}{l}\text { Filtradas por países ubicados } \\
\text { en Suramérica }\end{array}$ & 28 & 222 & 1 & 0 \\
\hline Publicadas en 2018 & 8 & 23 & 1 & 0 \\
\hline
\end{tabular}

Fuente: Elaboración propia en base a datos tomados de Elsevier (2018).

\section{Sensores remotos y teledetección}

Los métodos geoinformáticos de mayor difusión utilizados para relacionar efectivamente el cambio climático y sus consecuencias sobre los cultivos y las coberturas vegetales son sin duda los sensores remotos, debido a su gran versatilidad (Colditz y Dech 2007). De los métodos geoinformáticos (que usan una lectura directa del valor del píxel) se desprenden dos tipos de análisis, los cuales se pueden dar a partir de modelado de series de tiempo o de análisis de tendencias (regresión lineal simple).

\section{Análisis de regresión lineal}

Los análisis de regresión lineal consisten en el estudio de la dependencia de una variable respecto a otra variable independiente o explicativa, mediante una función de tipo lineal (Gujarati y Porter 2010). Esto se realiza con el fin de identificar tendencias crecientes o decrecientes en el total de la serie de tiempo, utilizando una recta de regresión cuya pendiente (positiva o negativa) suministre información de dicha tendencia (Gujarati y Porter 2010).

Dentro de este tipo de estudios se destaca el trabajo expuesto por Szymula Vicente (2014), en el que presenta un estudio de las sequías en la región noreste de Argentina a partir de series de tiempo tomadas del sensor MODIS. En ella se aprecia una clara disminución en los valores de NDVI 
y de NDWI, al utilizar líneas de tendencia gráficas en las cuales se observa una pendiente negativa en los periodos comprendidos entre el año 2001 y 2009. Este comportamiento es congruente con valores y modelaciones medidas a partir de estaciones meteorológicas, las cuales confirman que en este lapso de tiempo se presentó la sequía más fuerte de la historia para la región. Hammer, Kraft y Wheeler (2014) utilizan métodos econométricos simples para el análisis de series de tiempo de NDVI, obteniendo una tendencia lineal con pendiente negativa, debido a una anomalía generada por un fuerte periodo de sequía en la región de Pará, Brasil, para el periodo entre los años 2000 y 2008. Eckert et al. (2015) realizaron un estudio para la región de Mongolia en el que usaron análisis de series de tiempo. Utilizaron análisis de regresión lineal simple para hallar cambios en los usos del suelo a través del NDVI, a partir de imágenes del sensor MODIS; en ella encontraron tendencias negativas en las zonas donde se dieron cambios debido a deforestación, incendios forestales, actividades mineras y expansión urbana. Para el monitoreo de las variaciones de la captura de carbono estacionales e interanuales en bosques templados caducifolios del Parque Nacional Chequamegon-Nicollet, Wisconsin, USA, Tang et al. (2013) utilizaron Series de Tiempo de varios índices de vegetación, obtenidas del sensor MODIS. Para ello, generaron un modelo lineal que permitió estimar la variabilidad estacional e interanual del Intercambio Neto de Carbono del Ecosistema (NEE), y concluyeron que estos bosques maduros actuaron como un fuerte sumidero de carbono durante los 11 años de la serie. Sin embargo, dicho modelo estimó una disminución en la absorción de Carbono en los últimos años. Para su análisis estadístico utiliza correlaciones de Pearson y análisis de regresión lineal. Investigaciones más recientes como la de Bucha et al. (2017) realizan un análisis de Series de Tiempo de NDVI, utilizando modelos de Regresiones Lineales encontrando cambios en las temporadas de crecimiento y pérdidas de las hojas (Growing Season - GS), donde se retrasó la temporada de caída en 1.9 días por década y se alargó la temporada de crecimiento en 1.8 días. Xulu et al. (2018) aplicaron pruebas de Regresión Lineal Múltiples y de Mann-Kendall para determinar la asociación del NDVI y el NDII con las variables climáticas y establecer los efectos de la sequías sobre plantaciones forestales en Sudáfrica, confirmando tendencias negativas en los valores de NDVI entre 2014 y 2015.

\section{Análisis de regresión no lineal}

Aunque las aproximaciones lineales pueden funcionar bien y ser suficientemente explicativas de los fenómenos (Figueroa 2013), se debe tener en cuenta que muchos de estos fenómenos observables no se comportan de manera lineal, por lo que no pueden ser explicados o simulados por estos métodos. Las series de tiempo de temperatura y de Índices de Vegetación son un claro ejemplo de ello, presentando tendencias cíclicas que pueden ser mejor representados por modelos no lineales (Rivas M, López P y Velasco M 1993). Según Valencia, Anaya y Caro-Lopera (2016), aunque la modelación lineal se ha empleado en calibración de imágenes de satélite (la cual es el insumo para generar los IV y hacerle seguimiento a los cambios de esta), los datos satelitales presentan en su mayoría problemas de no normalidad, errores correlacionados, heterocedasticidad y valores extremos, por lo que la modelación no lineal es muy importante.

Saatchi et al. (2013) utilizan series de tiempo tomadas de los sensores de radar QSCAT y TRMM para encontrar la relación existente entre las sequías producidas por la acción del fenómeno del niño y los efectos sobre la selva amazónica, usando un Modelo Auto-Regresivo (ARMA). Encontraron que la sequía del año 2005 causó una fuerte disminución de la humedad del suelo, llevando el agua disponible para las plantas a niveles críticos durante periodos prolongados; esto causó la 
mortalidad de los árboles y aumentó la susceptibilidad a incendios forestales. Igualmente mencionan, que durante este mismo año, el sensor QSCAT determinó la extensión e intensidad de los impactos en el Amazonas, identificando las anomalías en los datos, cuestión que sugirió un efecto persistente de estrés hídrico sobre el dosel del bosque, el cual se mantuvo hasta el siguiente evento de sequía intensa del año 2010. Si las frecuencias en que se presentan las sequías se mantienen en lapsos de 5 a 10 años o se incrementan, se presentarían las primeras señales de una potencial degradación de la selva Amazónica a gran escala debido al cambio climático. Bravo Peña et al. (2013) utilizan series de tiempo anuales del Índice de Vegetación Mejorado (EVI), a partir del sensor MODIS para el análisis de 5 coberturas naturales del occidente, norte y noroeste de México durante el periodo 2000 a 2013. Sus hallazgos sugieren un decrecimiento de la Producción Primaria Aérea Bruta (PPA) en todas las coberturas analizadas, y aunque existen causas combinadas, se menciona la degradación causada por actividades antropogénicas como la ganadería y la reducción de las lluvias, que van del 20 al 40\% asociadas al cambio climático. Además, analizaron las series de tiempo por el método Mann Kendall Contextual, ampliamente utilizado en análisis meteorológicos. Son et al. (2012) monitorearon las sequías en la Cuenca Baja del Mekong, utilizando Series de Tiempo del Índice Vegetal de Temperatura de Aridez (TDVI), el cual se obtiene al combinar la Temperatura Superficial (LST) con el Índice Diferencial de Vegetación Normalizado (NDVI) tomadas del sensor MODIS. Este índice provee una mejor información de la vegetación y de las condiciones de humedad de la superficie; además, usa el Índice de Estrés Hídrico de Cultivo (CWSI) generado a partir de LST para obtener el contenido de humedad de la superficie en el mismo periodo de la estación seca. A partir de estos, identificaron una gran área de fuerte sequía para las temporadas comprendidas entre los años 2003 a 2006, donde se presentó la mayor afectación durante la estación seca del año 2005. Xu y Shen (2013) utilizaron el algoritmo de Análisis Harmónico de Series de Tiempo (HANTS) para reconstruir las series de temperatura superficial del Sensor MODIS en la región del Rio Yang Tse, China, en los lapsos donde esta se ve afectada por nubes o donde existen datos perdidos o nulos, lo que mejora significativamente la calidad de la serie.

Teniendo en cuenta la cantidad de metodologías existentes para el análisis de Series de Tiempo, Zhou et al. (2016) comparan los modelos más utilizados para su reconstrucción y análisis, entre los que se encuentran el Análisis Harmónico (HA), Suavizado de Whitaker (WS), Ajuste Asimétrico Gaussiano (AG), Ajuste Doble Logístico (DL) y Filtro de Savitzky Golay (SG). Los autores encontraron que el modelo que mejor se ajusta a latitudes tropicales es el SG, mientras que los modelos AG y DL tienen mayor rendimiento en latitudes boreales y, finalmente, los modelos HA y WS son estables para reconstrucciones globales.

Al ingresar las palabras clave "MODIS" AND "Time Series" AND "Linear Regression" en la base de datos científica Scopus, se encuentra, en primera instancia, un mayor número de investigaciones en el periodo comprendido entre 2006 y 2018, comparado con la búsqueda realizada para el numeral Modelado y Simulación Espacial; en esta última se observa un aumento gradual por año en número de investigaciones que contienen estos ítems de búsqueda.

Al observar la Figura $N^{\circ} 5$ logra apreciarse que la producción científica en los temas bajo estudio viene aumentando con el transcurrir de los últimos años, aunque en los criterios presentes no se obtiene una relación de las series de tiempo con el análisis de los índices de vegetación. Al agregar en este el criterio de búsqueda Vegetation Index se obtiene la Figura $N^{\circ} 6$, en la que se aprecia, igualmente, una alta producción científica. 
Figura $N^{\circ} 5$

Artículos presentados por año con criterios de búsqueda MODIS AND Time Series AND Linear Regression

Documents by year

25

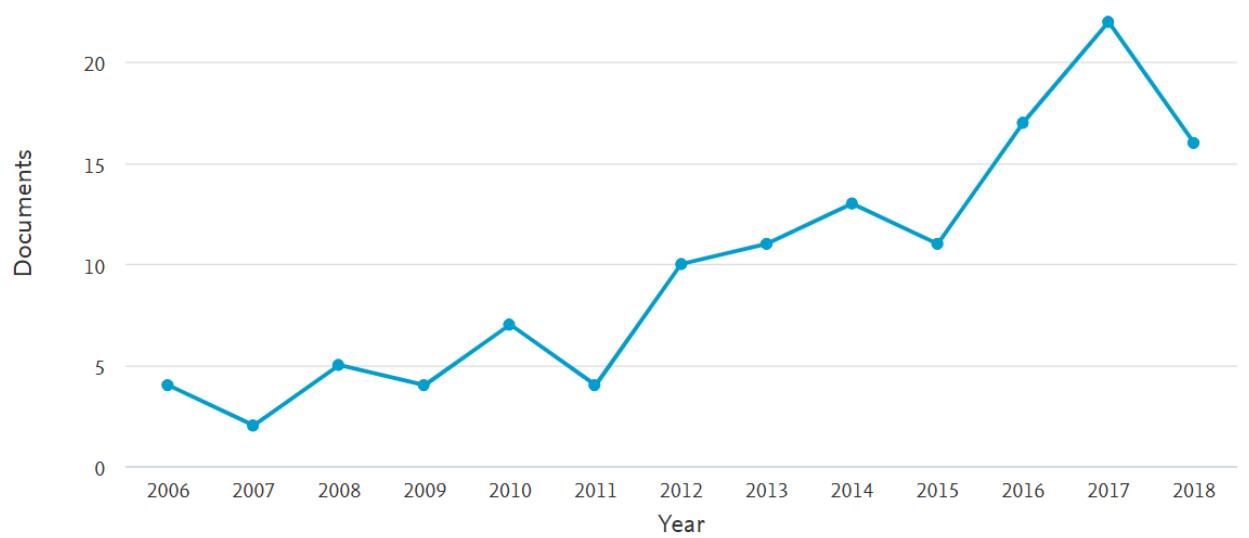

Fuente: (Elsevier 2018)

Figura $\mathrm{N}^{\circ} 6$

Artículos presentados por año con criterios de búsqueda MODIS AND Time Series AND Linear Regression AND Vegetation Index

Documents by year

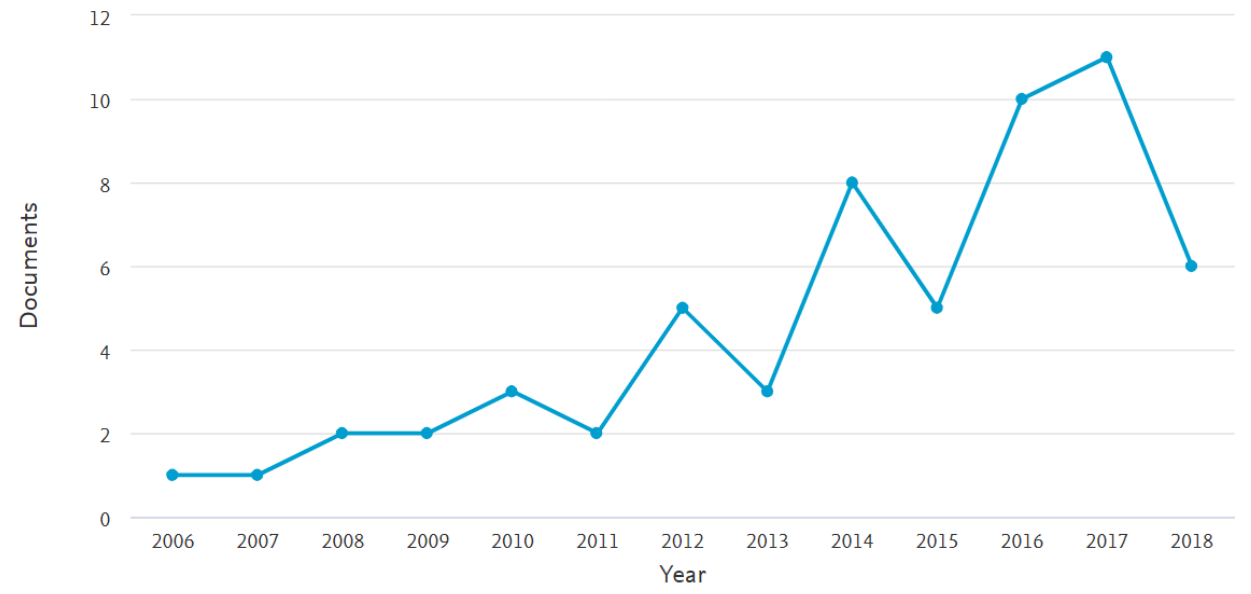

Fuente: (Elsevier 2018)

Al comparar la información obtenida entre las investigaciones desarrolladas por Modelado y Simulación Espacial y aquellas desarrolladas mediante sensores remotos y teledetección, particularmente con el sensor MODIS, se aprecia que la mayor densidad de investigaciones se da en el ámbito de la teledetección. Esto debido al fácil acceso a dicha información, que en su gran mayoría es posible adquirir de forma gratuita a través de diferentes servidores. 
Finalmente, si se establecen los criterios de búsqueda Time Series AND Nonlinear Regression AND Vegetation Index, se obtiene una marcada diferencia en la cantidad de resultados obtenidos, ya que solo 3 investigaciones se presentan en los últimos 15 años que concuerden con los criterios mencionados. Esto indica que en el campo investigativo de las series de tiempo obtenidas del sensor MODIS no se ha explorado con suficiencia los Modelos de Regresión No Lineales que concuerden con los productos de índices de vegetación (Ver Figura $N^{\circ} 7$ ), esto teniendo en cuenta que Zhou et al. (2016) realizan una recopilación de diferentes métodos de Regresión No Lineal para el análisis de Series de Tiempo.

El Cuadro $N^{\circ} 2$ muestra con mayor claridad las tendencias en cuanto al análisis utilizado en este grupo de investigaciones, donde no se provee como herramienta principal los análisis de regresión lineal $(R L)$ y de Regresión No Lineal (RNL); adicionalmente, se hace evidente la baja productividad investigativa para la región de Suramérica y principalmente para la región tropical, que comprende países como Colombia, Ecuador, Perú, Venezuela, Norte de Brasil, las Guayanas y Surinam, en los que el desarrollo ha sido incipiente.

\section{Figura $\mathrm{N}^{\circ} 7$}

Artículos presentados por año con criterios de búsqueda Time Series AND Nonlinear Regression AND Vegetation Index

Documents by year

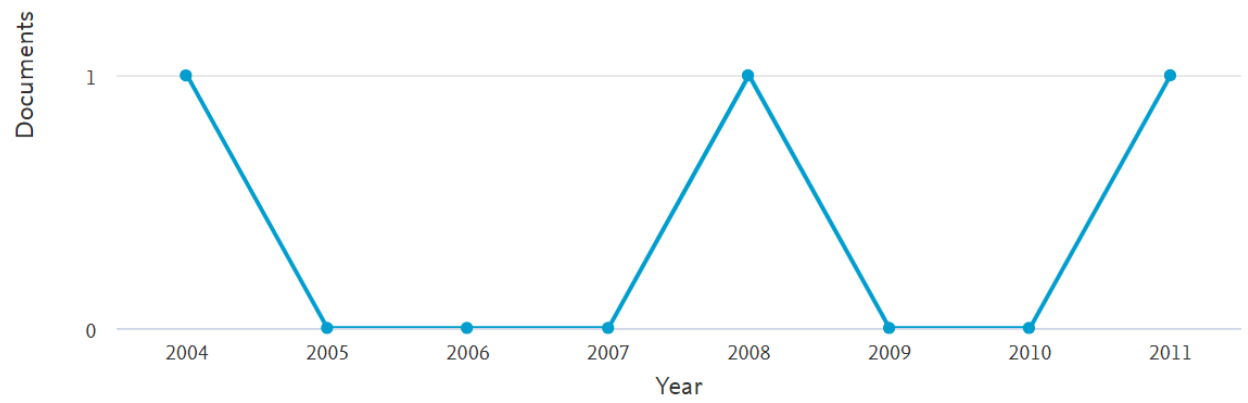

Fuente: (Elsevier 2018)

Cuadro $\mathrm{N}^{\circ} 2$

Criterios para la búsqueda de información de Series de Tiempo con Sensor MODIS, Modelos de Regresión Lineal y No Lineal e Índices de Vegetación

\begin{tabular}{|l|c|c|c|c|}
\hline & $\begin{array}{c}\text { "MODIS" } \\
\text { AND } \\
\text { "Time } \\
\text { Series" }\end{array}$ & $\begin{array}{c}\text { "MODIS" AND } \\
\text { "Time Series" } \\
\text { AND “Linear } \\
\text { Regression" }\end{array}$ & $\begin{array}{c}\text { "MODIS" AND } \\
\text { "Time Series" } \\
\text { AND “Linear } \\
\text { Regression" AND } \\
\text { "Vegetation Index" }\end{array}$ & $\begin{array}{c}\text { "Time Series" } \\
\text { AND “Nonlinear } \\
\text { Regression" } \\
\text { AND “Vegetation } \\
\text { Index" }\end{array}$ \\
\hline $\begin{array}{l}\text { Todos los } \\
\text { documentos }\end{array}$ & 3241 & 121 & 58 & 3 \\
\hline
\end{tabular}




\begin{tabular}{|l|c|c|c|c|}
\hline & $\begin{array}{c}\text { "MODIS" } \\
\text { AND } \\
\text { “Time } \\
\text { Series" }\end{array}$ & $\begin{array}{c}\text { "MODIS" AND } \\
\text { "Time Series" } \\
\text { AND “Linear } \\
\text { Regression" }\end{array}$ & $\begin{array}{c}\text { "MODIS" AND } \\
\text { "Time Series" } \\
\text { AND “Linear } \\
\text { Regression" AND } \\
\text { "Vegetation Index" }\end{array}$ & $\begin{array}{c}\text { "Time Series" } \\
\text { AND “Nonlinear } \\
\text { Regression" } \\
\text { AND “Vegetation } \\
\text { Index" }\end{array}$ \\
\hline $\begin{array}{l}\text { Solo revistas } \\
\text { académicas }\end{array}$ & 2258 & 99 & 51 & 3 \\
\hline $\begin{array}{l}\text { Solo textos de } \\
\text { Ciencias de la tierra, } \\
\text { relacionadas con } \\
\text { clima y calentamiento } \\
\text { global }\end{array}$ & 1894 & 86 & 41 & 3 \\
\hline $\begin{array}{l}\text { Filtradas por } \\
\text { paises ubicados en } \\
\text { Suramérica }\end{array}$ & 130 & 6 & 2 & 1 \\
\hline Publicadas en 2018 & 11 & 0 & 0 & 0 \\
\hline
\end{tabular}

Fuente: Elaboración propia en base a datos tomados de Elsevier (2018).

\section{Discusión y análisis}

Dentro de las diferentes líneas de investigación que se pueden ejercer dentro del campo de la geoinformática, en el área del análisis de los fenómenos climáticos, específicamente el aumento de la temperatura y su relación con la respuesta en las coberturas vegetales, se definen en el presente artículos dos líneas de investigación. La primera se denomina Modelado y Análisis de Geodatos, donde se destacan, por un lado, análisis estadísticos univariados o determinísticos y, por otro, los Modelos Climáticos Globales (GCM). Los GCM consisten en modelaciones matemáticas complejas en las que se destaca su resolución relativamente gruesa y su nivel de incertidumbre cuando se refina dicha resolución al introducir escalas de mayor detalle; por medio de ellas es posible generar predicciones del comportamiento del clima a largo plazo, considerando escenarios variables. Al ser los modelos GCM cómputos matemáticos, basados en variables climáticas, habría que recurrir igualmente a los sensores remotos para realizar una comparación con las tendencias de los Índices de Vegetación (IV) y, debido a su resolución espacial y temporal, no sería una opción adecuada para la elaboración de un modelo comparativo, pero sí complementario. Igualmente, los modelos determinísticos mencionados en el numeral A consisten en la utilización de información puntual de la cual se obtienen comportamientos espaciales a partir de interpolaciones determinísticas de los datos y donde la utilización de los sensores remotos, al igual que los modelos GCM, se reduce a una herramienta complementaria.

Si se tiene en cuenta el volumen de investigaciones presentadas en los últimos 10 años, puede observarse que no son muchas y solo 3 relacionan índices de vegetación en el análisis, por lo que se deduce que no es un método muy utilizado para el análisis de las series de tiempo de temperatura y su influencia en la salud de la vegetación.

Adicionalmente, dada la información presentada en el Cuadro $N^{\circ} 1$ y el Cuadro $N^{\circ} 2$, se observa que existe un vacío en la investigación en las regiones tropicales de Suramérica, que comprende naciones como Colombia, Ecuador, Perú, Venezuela, Guayanas, Surinam, Norte de Brasil y Bolivia. 
Aunque existen desarrollos en el análisis del cambio climático y su efecto sobre la selva amazónica, puede afirmarse que son insuficientes y que hace falta mayor investigación.

En cuanto al área de la teledetección, dentro del campo de la geoinformática se encuentra una mayor abundancia en este tipo de artículos de investigación, debido al fácil acceso para su desarrollo. Los sensores remotos proporcionan datos de temperatura y de índices de vegetación de manera simultánea, continua y con alta resolución, en casi toda la superficie de la tierra, y en el caso de los productos obtenidos del sensor MODIS, con continuas actualizaciones de los algoritmos de corrección. Sin embargo, no dejan de presentarse zonas en las que por la incidencia de nubosidad o por presencia de datos nulos se presenten vacíos en la información; es allí donde toman suma importancia los análisis de regresión no lineal que son utilizados en su mayoría para el ajuste y reconstrucción de las series de tiempo para proveer un patrón en el comportamiento de estos datos, eliminando datos extremos o anormales. Tanto las regresiones lineales como las no lineales permiten la construcción de las tendencias futuras de dichas series de tiempo y a la vez realizan una comparación adecuada entre datos de temperatura e índices de vegetación. Al comparar las investigaciones que combinan Series de Tiempo con Regresiones No Lineales e Índices de Vegetación, se observa efectivamente un bajo volumen en este aspecto, no queriendo decir esto que no existan, sino que aún no se desarrolla este tema con suficiencia.

\section{Conclusiones}

Se identifica una clara tendencia hacia el uso de técnicas de teledetección para el análisis de los elementos del clima (temperatura y precipitación) y su relación con los índices de vegetación. Esto debido a que los datos pueden ser analizados y comparados pixel a pixel, obteniendo tendencias muy precisas que relacionan Temperatura Superficial (LST) e Índices de Vegetación (IV). En los análisis de tendencias a partir de series de tiempo construidas con el uso de modelaciones matemáticas como los GCM se debe acudir a la teledetección para compararla con las afectaciones provocadas en las coberturas vegetales, ya que los GCM solo incorporan variables climáticas y atmosféricas. Las características mencionadas, sumadas a una resolución espacial gruesa, las hace menos apropiadas para el análisis de Series de Tiempo de LST contra IV, ya que las diferencias pueden generar altos niveles de incertidumbre.

El uso de los sensores remotos es común dentro de la comunidad científica, debido a su acceso libre, a la alta cantidad de información disponible, alta resolución espacial, temporal y espectral; todo un grupo de ventajas que juegan a su favor. Sin embargo, al revisar la literatura científica de las dos líneas propuestas en la presente taxonomía (Análisis de Regresión Lineal y Análisis de Regresión No Lineal), se observa que los análisis de RNL son utilizados principalmente para el ajuste de las series de tiempo y el relleno en los vacíos de la información, además de la identificación de tendencias, mientras que los análisis de RL son utilizados principalmente en identificación de tendencias. Por este motivo, en el análisis de series de tiempo, tanto para datos de Temperatura como Índices de Vegetación, es importante completar por medio del modelo la información faltante y luego identificar las tendencias crecientes y decrecientes en el tiempo. Adicionalmente, para la selección del modelo RNL más adecuado debe tenerse en cuenta la zona geográfica de aplicación, ya que algunos presentan mejor comportamiento dependiendo si se realizan en el trópico, en zonas australes o boreales. A pesar de todo el sustento matemático y 
estadístico presente para el análisis de las series de tiempo, la Figura $N^{\circ} 7$ indica que aún no se desarrolla en profundidad la temática de los Análisis RNL en combinación con datos de LST y IV. Por lo tanto, esta es un área donde se puede dar un progreso en las investigaciones, particularmente aquellas que relacionan el aumento gradual de la temperatura con las variaciones en la salud de las coberturas vegetales y su relación con el cambio climático.

Por otro lado, es necesario aumentar el volumen de investigaciones desarrolladas en las áreas tropicales de Sudamérica, dado que se han presentado a la comunidad científica muy pocos estudios. Esto indica que aún faltan fenómenos y conceptos por evidenciar en cuanto al cambio climático y su efecto sobre la selva amazónica y los cultivos de toda la región.

Finalmente, diversas investigaciones citadas en el presente artículo coinciden en la degradación de las coberturas vegetales debido a factores de origen antrópico, como cambios de uso del suelo, tala de bosques o ampliación de la frontera agrícola, entre otros. Sin embargo, también se evidencia en ellos que existe un gradual deterioro de la capa vegetal, debido a la intensificación de los periodos de sequía y del fenómeno del niño, por lo que próximas investigaciones deben enfocarse en encontrar una relación sustentada entre esta degradación y el proceso de cambio climático.

\section{Referencias bibliográficas}

ANAYA ACEVEDO, J. y VALENCIA HERNANDEZ, G., 2013. Fenología de ambientes tropicales en el marco de la Teledetección. Revista Internacional de Ciencia y Tecnología de la Información Geográfica (GeoFocus), vol. 13, no. 2, pp. 195-211.

ANAYA, J.A., CHUVIECO, E. y PALACIOS, A., 2008. Estimación de biomasa aérea en Colombia a partir de imágenes MODIS. Revista de Teledetección, vol. 30, pp. 5-22.

ANAYA, J.A., COLDITZ, R.R. y VALENCIA, G., 2015. Land Cover Mapping of a Tropical Region by Integrating Multi-Year Data into an Annual Time Series. Remote Sensing [en línea], vol. 7, no. 12, pp. 16274-16292. ISSN 2072-4292. DOI 10.3390/rs71215833. Disponible en: http://www.mdpi. com/2072-4292/7/12/15833/htm.

ANDERSON, T.R., HAWKINS, E. y JONES, P.D., 2016. CO2, the greenhouse effect and global warming: from the pioneering work of Arrhenius and Callendar to today's Earth System Models. Endeavour, vol. 40, no. 3, pp. 178-187. ISSN 01609327. DOI 10.1016/j.endeavour.2016.07.002.

ARDANUY, J. y REY, L., 2012. Breve introducción a la bibliometría. Barcelona: Universitat De Barcelona.

ARMENTA, G., DORADO, J., RODRIGUEZ, A. y RUIZ, J., 2014. Escenarios De Cambio Climático Para Precipitación Y Temperaturas En Colombia. Instituto de Hidrología, Meteorología y Estudios Ambientales de Colombia IDEAM, no. 1, pp. 274.

BARKER, T., 2007. Climate Change 2007 : An Assessment of the Intergovernmental Panel on Climate Change. En: R.K. PACHAURI y A. REISINGER (eds.), Change [en línea], vol. 446, no. November, 
pp. 12-17. ISSN 10035494. DOI 10.1256/004316502320517344. Disponible en: http://www.ipcc.ch/ pdf/assessment-report/ar4/syr/ar4_syr.pdf.

BARROS, V., 2005. El Cambio Climático Global ¿Cuántas Catástrofes Antes de Actuar? 2da ed. Buenos Aires: s.n. ISBN 987108188-X.

BONAN, G.B., 2008. Forests and Climate Change: Forcings, Feedbacks, and the Climate Benefits of Fiorests. Science [en línea], vol. 320, no. 5882, pp. 1444-1449. ISSN 1095-9203. DOI 10.1126/ science.1155121. Disponible en: /home/bayer-a/5_Literature/Papers/Bonan2008_C-cycle_feedback_forests.pdf\%5Cnhttp://www.ncbi.nlm.nih.gov/pubmed/18556546.

BRAVO PEÑA, L.C., CASTELLANOS VILLEGAS, A., ALATORRE CEJUDO, L.C. y TORRES OLAVE, M.E., 2013. Tendencias temporales del Índice Mejorado de la Vegetación (EVI) en cinco coberturas naturales del Occidente, Norte Y Noroeste de México durante el periodo 2000-2013. Laboratorio Nacional de Geoprocesamiento de Información Fitosanitaria (langif.uas/p.mx).

BUCHA, T. y KOREN, M., 2017. Phenology of the beech forests in the western carpathians from MODIS for 2000-2015. IForest, vol. 10, no. 3, pp. 537-546. ISSN 19717458. DOI 10.3832/ifor2062-010.

CHAN, K.K.Y. y XU, B., 2013. Perspective on remote sensing change detection of Poyang Lake wetland. Annals of GIS, vol. 19, no. 4, pp. 231-243. ISSN 19475683. DOI 10.1080/19475683.2013.843589.

CHEN, L., JIN, Z., MICHISHITA, R., CAI, J., YUE, T., CHEN, B. y XU, B., 2014. Dynamic monitoring of wetland cover changes using time-series remote sensing imagery. Ecological Informatics, vol. 24, pp. 17-26. ISSN 15749541. DOI 10.1016/j.ecoinf.2014.06.007.

CINU (CENTRO DE INFORMACIÓN DE LAS NACIONES UNIDAS), 2016. El clima mundial bate nuevos récords entre enero y junio de 2016. Sala de prensa.

COLDITZ, R.R. y DECH, S., 2007. Time Series Generation and Classification of MODIS Data for Land Cover Mapping. S.I.: Universität Würzburg.

CONDE, A.C. y GAY GARCÍA, C., 2008. Guía para la generación de escenarios de cambio climático a escala regional. 2008. Mexico D.F.: s.n.

ECKERT, S., HÜSLER, F., LINIGER, H. y HODEL, E., 2015. Trend analysis of MODIS NDVI time series for detecting land degradation and regeneration in Mongolia. Journal of Arid Environments, vol. 113, pp. 16-28. ISSN 1095922X. DOI 10.1016/j.jaridenv.2014.09.001.

ECMWF, 2017. 2016 was warmest year yet, ECMWF data show. .

ELSEVIER, 2018. Scopus: Acces and Use Support Center. .

FIGUEROA, S.C., 2013. Modelo de Regresión No Lineal. S.I.: Universidad de Buenos Aires. 
GARCÍA-MORA, T.J. y MAS, J.-F., 2011. Presentación del sensor MODIS. Aplicaciones del sensor MODIS para el monitoreo del territorio. 1 ed. Mexico D.F.: Secretaría de Medio Ambiente y Recursos Naturales (SEMARNAT); Instituto Nacional de Ecología (INE); Universidad Nacional Autónoma de México (UNAM); Centro de Investigaciones en Geografía Ambiental (CIGA), pp. 11-24. ISBN 978607-7908-55-5.

GIBBES, C., SOUTHWORTH, J. y KEYS, E., 2009. Wetland conservation: Change and fragmentation in Trinidad's protected areas. Geoforum, vol. 40, no. 1, pp. 91-104. ISSN 00167185. DOI 10.1016/j. geoforum.2008.05.005.

GUJARATI, D.N. y PORTER, D.C., 2010. ECONOMETRÍA. 5 edición. Mexico D.F.: Mc Graw Hill/Irwin, Inc. ISBN 9786071502940.

HAMMER, D., KRAFT, R. y WHEELER, D., 2014. Alerts of forest disturbance from MODIS imagery. International Journal of Applied Earth Observation and Geoinformation, vol. 33, no. 1, pp. 1-9. ISSN 15698432. DOI 10.1016/j.jag.2014.04.011.

HANSEN, M.C. y LOVELAND, T.R., 2012. A review of large area monitoring of land cover change using Landsat data. Remote Sensing of Environment [en línea], vol. 122, pp. 66-74. [Consulta: 20 enero 2014]. ISSN 00344257. DOI 10.1016/j.rse.2011.08.024. Disponible en: http://linkinghub.elsevier.com/retrieve/pii/S0034425712000314.

HERMOSILLA, T., WULDER, M.A., WHITE, J.C., COOPS, N.C. y HOBART, G.W., 2015. An integrated Landsat time series protocol for change detection and generation of annual gap-free surface reflectance composites. Remote Sensing of Environment, vol. 158, pp. 220-234. ISSN 00344257. DOI 10.1016/j.rse.2014.11.005.

HUETE, A.R., LIU, H.Q., BATCHILY, K. y VAN LEEUWEN, W., 1997. A comparison of vegetation indices over a global set of TM images for EOS-MODIS. Remote Sensing of Environment, vol. 59, no. 3, pp. 440-451. ISSN 00344257. DOI 10.1016/S0034-4257(96)00112-5.

IDEAM, 2012. Glaciares de Colombia. Más que montañas con hielo. Bogotá, D.C., Colombia: Comité de Comuniciaciones y Publicaciones del IDEAM. ISBN 9789588067575.

IDEAM, 2016. EL NIÑO CONTINÚA EN SU FASE DE MAYOR INTENSIDAD. Sala de prensa.

IPCC, 2014. Cambio Climático 2014: informe de síntesis. Contribución de los Grupos I, II y III al Quinto Informe de Evaluación del Grupo de Expertos sobre el Cambio Climático. Primera Pu. Ginebra, Suiza: s.n. ISBN 9789291693436.

KLEMAS, V., 2013. Remote sensing of emergent and submerged wetlands: an overview. International Journal of Remote Sensing, vol. 34, no. 18, pp. 6286-6320. ISSN 13665901. DOI 10.1080/01431161.2013.800656.

LI, M., QU, J.J. y HAO, X., 2010. Investigating phenological changes using MODIS vegetation indices in deciduous broadleaf forest over continental U.S. during 2000-2008. Ecological 
Informatics [en línea], vol. 5, no. 5, pp. 410-417. [Consulta: 5 diciembre 2013]. ISSN 15749541. DOI 10.1016/j.ecoinf.2010.04.002. Disponible en: http://linkinghub.elsevier.com/retrieve/pii/ S1574954110000543.

LI, Y., TAO, H., SU, B., KUNDZEWICZ, Z.W. y JIANG, T., 2019. Impacts of $1.5^{\circ} \mathrm{C}$ and $2^{\circ} \mathrm{C}$ global warming on winter snow depth in Central Asia. Science of the Total Environment, vol. 651, pp. 28662873. ISSN 0048-9697. DOI 10.1016/j.scitotenv.2018.10.126.

LIVADA, I., SYNNEFA, A., HADDAD, S., PAOLINI, R., GARSHASBI, S., ULPIANI, G., FIORITO, F., VASSILAKOPOULOU, K., OSMOND, P. y SANTAMOURIS, M., 2019. Time series analysis of ambient air-temperature during the period 1970-2016 over Sydney, Australia. Science of the Total Environment, vol. 648, pp. 1627-1638. ISSN 18791026. DOI 10.1016/j.scitotenv.2018.08.144.

MA, C., PAN, S., WANG, G., LIAO, Y. Y XU, Y.P., 2016. Changes in precipitation and temperature in Xiangjiang River Basin, China. Theoretical and Applied Climatology, vol. 123, no. 3-4, pp. 859-871. ISSN 14344483. DOI 10.1007/s00704-015-1386-1.

MISHRA, N.S., GHOSH, S. y GHOSH, A., 2012. Fuzzy clustering algorithms incorporating local information for change detection in remotely sensed images. Applied Soft Computing Journal, vol. 12, no. 8, pp. 2683-2692. ISSN 15684946. DOI 10.1016/j.asoc.2012.03.060.

MUDELSEE, M., 2018. Trend analysis of climate time series: A review of methods. Earth-Science Reviews, pp. \#pagerange\#. ISSN 00128252. DOI 10.1016/j.earscirev.2018.12.005.

OTTINGER, M., KUENZER, C., LIU, G., WANG, S. y DECH, S., 2013. Monitoring land cover dynamics in the Yellow River Delta from 1995 to 2010 based on Landsat 5 TM. Applied Geography, vol. 44, pp. 53-68. ISSN 01436228. DOI 10.1016/j.apgeog.2013.07.003.

PARIHAR, S.M., SARKAR, S., DUTTA, A., SHARMA, S. y DUTTA, T., 2013. Characterizing wetland dynamics: A post-classification change detection analysis of the East Kolkata Wetlands using open source satellite data. Geocarto International, vol. 28, no. 3, pp. 273-287. ISSN 10106049. DOI 10.1080/10106049.2012.705337.

RAJASEKAR, U. y WENG, Q., 2009. Application of Association Rule Mining for Exploring the Relationship between Urban Land Surface Temperature and Biophysical/Social Parameters. Photogrammetric Engineering \& Remote Sensing, vol. 75, no. 4, pp. 385-396. ISSN 00991112. DOI 10.14358/PERS.75.4.385.

RAMACHANDRAN, B., JUSTICE, C.O. y ABRAMS, M.J., 2011. Land Remote Sensing and Global Environmental Change. 1 ed. New York, NY: Springer New York. Remote Sensing and Digital Image Processing. ISBN 978-1-4419-6748-0.

RESHMIDEVI, T. V., NAGESH KUMAR, D., MEHROTRA, R. y SHARMA, A., 2018. Estimation of the climate change impact on a catchment water balance using an ensemble of GCMs. Journal of Hydrology, vol. 556, pp. 1192-1204. ISSN 00221694. DOI 10.1016/j.jhydrol.2017.02.016. 
RINCÓN ROMERO, M.E., JARVIS, A. y MULLIGAN, M., 2012. Cobertura vegetal de Colombia actualizada a partir de imágenes MODIS, disponible a través de RENATA. Renata, vol. 2, no. 4, pp. 12-27.

RIVAS M, G., LÓPEZ P, L.A. y VELASCO M, A., 1993. Regresión no lineal. Revista Colombiana de Estadística, vol. 14, no. 27, pp. 1-15.

RODRÍGUEZ-ERASO, N., PABÓN-CAICEDO, J.D., BERNAL-SUÁREZ, N.R. y MARTíNEZ-COLLANTES, J., 2010. Cambio climático y su relación con el uso del suelo en los Andes colombianos. 1 ed. Bogotá, D.C.: Guerra Editores. ISBN 9789588343426.

RODRÍGUEZ ERASO, N., ARMENTERAS-PASCUAL, D. y ALUMBREROS, J.R., 2013. Land use and land cover change in the Colombian Andes: Dynamics and future scenarios. Journal of Land Use Science, vol. 8, no. 2, pp. 154-174. ISSN 1747423X. DOI https://doi.org/10.1080/1747423X.2011.650228.

SAATCHI, S., ASEFI-NAJAFABADY, S., MALHI, Y., ARAGÃO, L.E.O.C., ANDERSON, L.O., MYNENI, R.B. y NEMANI, R., 2013. Persistent effects of a severe drought on Amazonian forest canopy. Proceedings of the National Academy of Sciences of the United States of America, vol. 110, no. 2, pp. 56570. ISSN 1091-6490. DOI 10.1073/pnas.1204651110.

SALLES, R., BELLOZE, K., PORTO, F., GONZALEZ, P.H. y OGASAWARA, E., 2018. Nonstationary time series transformation methods: An experimental review. Knowledge-Based Systems, vol. 164, pp. 274-291. ISSN 09507051. DOI 10.1016/j.knosys.2018.10.041.

SETIAWAN, Y., YOSHINO, K. y PRASETYO, L.B., 2014. Characterizing the dynamics change of vegetation cover on tropical forestlands using $250 \mathrm{~m}$ multi-temporal MODIS EVI. International Journal of Applied Earth Observation and Geoinformation, vol. 26, no. 1, pp. 132-144. ISSN 15698432. DOI 10.1016/j.jag.2013.06.008.

SHI, C., JIANG, Z.H., CHEN, W.L. y LI, L., 2018. Changes in temperature extremes over China under $1.5^{\circ} \mathrm{C}$ and $2{ }^{\circ} \mathrm{C}$ global warming targets. Advances in Climate Change Research, vol. 9, no. 2, pp. 120-129. ISSN 16749278. DOI 10.1016/j.accre.2017.11.003.

SON, N.T., CHEN, C.F., CHEN, C.R., CHANG, L.Y. y MINH, V.Q., 2012. Monitoring agricultural drought in the lower mekong basin using MODIS NDVI and land surface temperature data. International Journal of Applied Earth Observation and Geoinformation, vol. 18, no. 1, pp. 417-427. ISSN 15698432. DOI 10.1016/j.jag.2012.03.014.

SONG, X. y BO, C., 2011. Change detection using Change Vector Analysis from Landsat TM images in Wuhan. Procedia Environmental Sciences, vol. 11, no. PART A, pp. 238-244. ISSN 18780296. DOI 10.1016/j.proenv.2011.12.037.

SUN, H., WANG, A., ZHAI, J., HUANG, J., WANG, Y., WEN, S., ZENG, X. y SU, B., 2018. Impacts of global warming of $1.5^{\circ} \mathrm{C}$ and $2.0^{\circ} \mathrm{C}$ on precipitation patterns in China by regional climate model (COSMO-CLM). Atmospheric Research, vol. 203, no. October 2017, pp. 83-94. ISSN 01698095. DOI 10.1016/j.atmosres.2017.10.024. 
SZYMULA VICENTE, J.P., 2014. Análisis de la evolución de sequías con metodologías de teledetección. S.I.: Universidad Nacional del Litoral.

TANG, X., WANG, Z., XIE, J., LIU, D., DESAI, A.R., JIA, M., DONG, Z., LIU, X. y LIU, B., 2013. Monitoring the seasonal and interannual variation of the carbon sequestration in a temperate deciduous forest with MODIS time series data. Forest Ecology and Management, vol. 306, pp. 150-160. ISSN 03781127. DOI 10.1016/j.foreco.2013.06.032.

TURNER, M.G. y GARDNER, R.H., 2015. Landscape disturbance dynamics. En: SPRINGER-VERLAG (ed.), Landscape Ecology in Theory and Practice: Pattern and Process. New York: s.n., pp. 175-228. ISBN 9781493927944.

VALENCIA, G., PEREZ, H., CASTRO, C., DURANGO, C. y ARIAS, C., 2017. CAPÍTULO 2: Geoinformática. En: E. SERNA (ed.), Geoinformática aplicada con Aprendizaje Basado en Problemas. Medellín: Editorial Instituto Antiqueño de Investigación, pp. 20-28. ISBN 978-958-59127-7-9.

VALENCIA, G.M., ANAYA, J.A. y CARO-LOPERA, F.J., 2016. Implementación y evaluación del modelo Landsat Ecosystem Disturbance Adaptive Processing System ( LEDAPS ): estudio de caso en los Andes colombianos. Revista de Teledetección, vol. 46, pp. 83-101. DOI http://dx.doi.org/10.4995/ raet.2016.3582.

VARGAS CUERVO, G. y GÓMEZ, C.E., 2003. La desertificación en Colombia y el cambio global. Cuadernos de Geografía: Revista Colombiana de Geografía, no. 12, pp. 121-134. ISSN 2256-5442.

VILARDY, S.P., GONZÁLEZ, J.A., MARTÍN-LÓPEZ, B. y MONTES, C., 2011. Relationships between hydrological regime and ecosystem services supply in a Caribbean coastal wetland: a social-ecological approach. Hydrological Sciences Journal, vol. 56, no. 8, pp. 1423-1435. ISSN 0262-6667. DOI 10.1080/02626667.2011.631497.

VILLERS-RUIZ, L. y TREJO-VAZQUEZ, I., 1998. Impacto del cambio climático en los bosques y áreas naturales protegidas de México. Interciencia, vol. 23, no. 1, pp. 10-19.

VIOLA, F.M., PAIVA, S.L.D. y SAVI, M.A., 2010. Analysis of the global warming dynamics from temperature time series. Ecological Modelling, vol. 221, no. 16, pp. 1964-1978. ISSN 03043800. DOI 10.1016/j.ecolmodel.2010.05.001.

VOGELMANN, J.E., XIAN, G., HOMER, C. y TOLK, B., 2012. Monitoring gradual ecosystem change using Landsat time series analyses: Case studies in selected forest and rangeland ecosystems. Remote Sensing of Environment, vol. 122, pp. 92-105. ISSN 00344257. DOI 10.1016/j.rse.2011.06.027.

WENG, Q., 2009. Thermal infrared remote sensing for urban climate and environmental studies: Methods, applications, and trends. ISPRS Journal of Photogrammetry and Remote Sensing [en línea], vol. 64, no. 4, pp. 335-344. [Consulta: 12 noviembre 2013]. ISSN 09242716. DOI 10.1016/j.isprsjprs.2009.03.007. Disponible en: http://linkinghub.elsevier.com/retrieve/pii/ S092427160900046X. 
WENG, Q., LU, D. y SCHUBRING, J., 2004. Estimation of land surface temperature-vegetation abundance relationship for urban heat island studies. Remote Sensing of Environment, vol. 89, no. 4, pp. 467-483. ISSN 00344257. DOI 10.1016/j.rse.2003.11.005.

WOFSY, S.C., ZHANG, X., QIN, D., MANNING, M., CHEN, Z., MARQUIS, M. y AVERYT, K.B., 2007. Couplings Between Changes in the Climate System and Biogeochemistry. Climate Change 2007: The Physical Science Basis, vol. 21, no. 7, pp. 499-587.

WORD METEOROLOGICAL ORGANIZATION (WMO), 2017. La Organización Meteorológica Mundial confirma que 2016 es el año más caluroso jamás registrado, con una temperatura media superior en aproximadamente $1,1^{\circ} \mathrm{C}$ a la de la era preindustrial. .

XU, Y. y SHEN, Y., 2013. Reconstruction of the land surface temperature time series using harmonic analysis. Computers \& Geosciences, vol. 61, pp. 126-132. ISSN 00983004. DOI 10.1016/j. cageo.2013.08.009.

XU, Y., ZHOU, B.T., WU, Jie, HAN, Z.Y., ZHANG, Y.X. y WU, Jia, 2017. Asian climate change under 1.5-4 ${ }^{\circ} \mathrm{C}$ warming targets. Advances in Climate Change Research, vol. 8, no. 2, pp. 99-107. ISSN 16749278. DOI 10.1016/j.accre.2017.05.004.

XULU, S., PEERBHAY, K., GEBRESLASIE, M. y ISMAIL, R., 2018. Drought Influence on Forest Plantations in Zululand, South Africa, Using MODIS Time Series and Climate Data. Forest, vol. 9, no. 528, pp. 1-15. DOI 10.3390/f9090528.

ZEDLER, J.B. y KERCHER, S., 2005. WETLAND RESOURCES: Status, Trends, Ecosystem Services, and Restorability. Annual Review of Environment and Resources, vol. 30, no. 1, pp. 39-74. ISSN 1543-5938. DOI 10.1146/annurev.energy.30.050504.144248.

ZHAO, M. y RUNNING, S.W., 2010. Drought-induced reduction in global terrestrial net primary production from 2000 through 2009. Science, vol. 329, no. 5994, pp. 940-943. ISSN 00368075. DOI 10.1126/science.1192666.

ZHOU, J., JIA, L., MENENTI, M. y GORTE, B., 2016. On the performance of remote sensing time series reconstruction methods - A spatial comparison. Remote Sensing of Environment, vol. 187, pp. 367-384.

ZHOU, T., CHEN, X., WU, B., GUO, Z., SUN, Y., ZOU, L., MAN, W., ZHANG, L. y HE, C., 2017. A Robustness Analysis of CMIP5 Models over the East Asia-Western North Pacific Domain. Engineering, vol. 3, no. 5, pp. 773-778. ISSN 20958099. DOI 10.1016/J.ENG.2017.05.018.

ZURQANI, H.A., POST, C.J., MIKHAILOVA, E.A., SCHLAUTMAN, M.A. y SHARP, J.L., 2018. Geospatial analysis of land use change in the Savannah River Basin using Google Earth Engine. International Journal of Applied Earth Observation and Geoinformation, vol. 69, no. December 2017, pp. 175-185. ISSN 03032434. DOI 10.1016/j.jag.2017.12.006. 